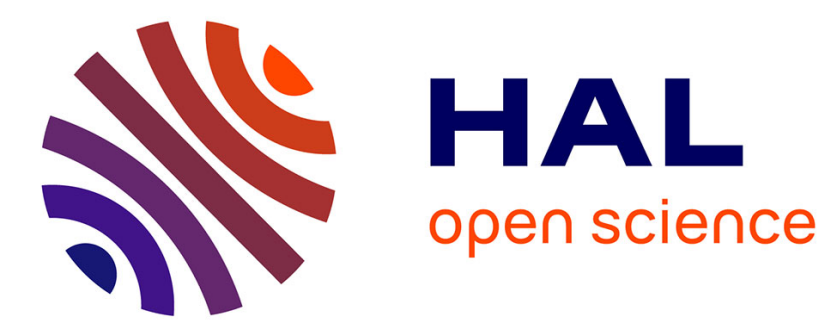

\title{
Normative multi-agent approach to support collaborative work in distributed tangible environments
}

Catherine Garbay, Fabien Badeig, Jean Caelen

\section{To cite this version:}

Catherine Garbay, Fabien Badeig, Jean Caelen. Normative multi-agent approach to support collaborative work in distributed tangible environments. CSCW Computer Supported Cooperative Work, Feb 2012, Seattle, Washington, United States. pp.83-86, 10.1145/2141512.2141548 . hal-00739129

\section{HAL Id: hal-00739129 \\ https://hal.science/hal-00739129}

Submitted on 5 Oct 2012

HAL is a multi-disciplinary open access archive for the deposit and dissemination of scientific research documents, whether they are published or not. The documents may come from teaching and research institutions in France or abroad, or from public or private research centers.
L'archive ouverte pluridisciplinaire HAL, est destinée au dépôt et à la diffusion de documents scientifiques de niveau recherche, publiés ou non, émanant des établissements d'enseignement et de recherche français ou étrangers, des laboratoires publics ou privés. 


\section{Normative multi-agent approach to support collaborative work in distributed tangible environments.}

Catherine Garbay

Laboratoire d'Informatique de

Grenoble-CNRS

Centre Equation 4 - UFR

IM2AG

BP 53 - 38041 Grenoble

Cedex 9 - France

catherine.garbay@imag.fr

Fabien Badeig

Laboratoire d'Informatique de

Grenoble-CNRS

Centre Equation 4 - UFR

IM2AG

BP 53 - 38041 Grenoble

Cedex 9 - France

Fabien.badeig@imag.fr

Jean Caelen

Laboratoire d'Informatique de

Grenoble-CNRS

220 Rue de la Chimie

BP 53 - 38041 Grenoble

Cedex 9 - France

jean.caelen@imag.fr

Copyright is held by the author/owner(s)

CSCW'12, February 11-15, 2012, Seattle, Washington, USA

ACM 978-1-4503-0556-3/12/02.

\begin{abstract}
We propose a design for collaborative support system in distant tangible environments, in the framework of activity theory. We model collaboration as driven by individualcentered and group-centered rules. Context sharing is core to this process, but reveals difficult in the case of distant tangible communication. We propose to model collaboration as a trace-based process in which tangible object traces are stored, analyzed, enriched and shared. We draw on a normative multi-agent approach in which explicit norms are meant to operate at various levels, from the physical to the social level. These norms do not act as a prerequisite, or as a way to place a priori constraints on action. Rather they result in a set of signs situating the activity. Such design offers novel ways for embedding activity theory in the current trend of socio-physical computing.
\end{abstract}

\section{Author Keywords}

Collaboration architectures; Computer-mediated communication; Community analysis and support, virtual or physical.

\section{ACM Classification Keywords}

H.5.3 [Information interfaces and presentation]: Group and organization interfaces

\section{General Terms}

Design, Human Factors 


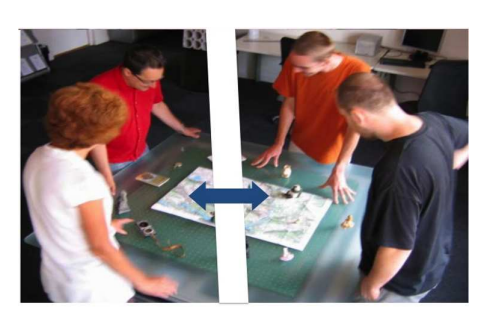

Figure 1: Working on distributed tangible surfaces.

\section{Introduction}

This research is conducted in the framework of a project called IMAGIT [7] whose objective is the management of distant interactive surfaces supporting tangible and virtual objects (Figure 1). The table, called TangiSense, allows the detection and identification of objects equipped with RFID tags placed on its surface. It is designed as a matrix of antennas and may be seen as a magnetic retina offering a spatial and temporal resolution compatible with the real-time detection of moving objects. Each RFID antenna is further equipped with 4 multicolor light emitting diodes (leds). These diodes may be lit underneath tangible objects, for example to assess a move. They may also be considered as virtual objects, and act as representatives of tangible objects. New models are necessary to think human collaboration in the context of distant tangible communication. We propose a design guided by activity theory [5] in which individual and group-level activities co-evolve under various laws: a proper coupling between the individual internal context and the group external context is core to sustain the collaboration process [4]. In the proposed framework, collaboration is modeled as a trace-based process in which tangible objects traces are stored, analyzed, enriched and shared. We moreover draw on a normative multi-agent approach [1] in which explicit norms are meant to operate at various levels, from the tangible object to the group level.

\section{State of the art}

According to activity theory [2], individual and group activity co-evolve in a context-dependent way, they are driven according to certain rules and conventions, and depend on the actors roles and resources, as well as their organizations. Context is defined as the coupling of two main components, internal (mental context, private objectives) and external (physical and social environment in which activity develops) [4]. Human activity is a process driven by attentional and intentional focusing, that shape the individual internal context. This process is further mediated by the individual external context, which evolves along group-based activity. The mutual sharing and shaping of both internal and external contexts is core to mutual understanding and collaboration. This is hampered in the case of distant communication, due to the absence of some signs of dialogue.

In tangible spaces, communication is embodied in the physical objects, which may be designed as coordination objects and raise action. In [6] for example, visual information is considered as a conversational resource in collaborative tasks, to maintain mutual awareness, ground conversation, and ease mutual understanding. In [9], tangible objects are used as resources to support epistemic action, be it oriented toward the physical or numerical world. According to [3], collaboration involves presentation / acceptation acts. These conversational acts may be verbal or involve gestural and facial expression. A variety of signal, signs and symbols finally constitute the traces on which collaboration draws. To face the difficulties of distant tangible communication, we propose that collaboration be modeled as a trace-based process in which tangible objects moves are stored, analyzed and communicated as traces of human activity. Specific tangible objects will be used in this process as so-called tangigets to formalize signs of dialog and support the coordination of action.

To design collaborative support systems, a major issue is to preserve the spontaneity and fluidity of human activity while ensuring the consistency and proper coordination action [8]. The community "Coordination, Organization, Institutions and Norms in Agent Systems" (http://www.pcs.usp.br/ coin/) proposes the notion of normative agent to approach coordination as a social paradigm. Behavior in such agents is 
not only guided by their mere individual objectives but also regulated by norms specifying which actions are considered as legal or not by the group. Norms are specified in a declarative way, they may be adopted or not by the agents, and adapted to cope with the evolution of context [1]. The purpose of our design is not to drive human action. Rather, it is to provide a frame for human action, in the form of normative policies that operates at various levels throughout the system. These norms may be individual (implicit, private and conflicting) or collective (explicit, shared and agreed). They are not meant to act as a prerequisite, or as a way to constraint action. Rather, they result in a set of signs enriching the trace and therefore situating the activity.

\section{Proposed Design}

To benefit from the tangibility offered by the infrastructure at hand, we propose to design dedicated tangible objects to support distant communication and use them to produce signs and traces of conversational activity. These tangible objects, similar to the more traditional widgets, are called tangigets. Tangigets may for example be used to ask for a break or designate a zone. Being physical objects, their appearance is not meant to change. However, led display underneath tangible objects is managed to assess user action. In addition, to support the need for consistent information display through distributed platforms, tangible objects may be virtually represented on distant surfaces via led display

Collaboration is modeled as a normative process coupling together a physical space (tangible objects), an informational space (traces of activity), a processing space (agents), and a normative space. Some agents are in charge of application management and visualization, and participate to the regulation of the whole application and therefore act at a global level. A second type of agents equip tangible objects and operate at a local level. Both agent behaviors are regulated by norms they have deposited in the normative space. Traces reflect and characterize the activity of humans and agents. They are filtered by norms, whose role is to check their properties under various criteria. Any trace is considered as a set of tuples $\langle($ property; value $)\rangle$, in which property are typed: $p=$ name : consistency : privacy, to register their compliance to the norms. The consistency slot indicates whether the property is valid or not (a tangible object move for example may have to obey some rule). The privacy slot indicates whether or not the property is accessible to distant agents (the transmission of tangible object to distant tables move may for example be restricted to some specific situations). Norms operate at several levels in the organization and express consistency and privacy rules operating at the infrastructure level (e.g. consistency of tangible object handling), at the actor individual level (e.g. privacy of some actions), and at the public level (e.g. expression of consistency rules at the group level). Their role is not to prevent action, but rather to evaluate its compliance. This evaluation results in trace property modifications, that may further be processed under various viewpoints (e.g. to provide dedicated visual feedback, or as a way to regulate further communication).

The agents are designed under JADE (http://jade.tilab.com), a framework implemented in Java. JADE handles dedicated primitives for the inter/intra platform communication and therefore reveals particularly well adapted to the integration of middleware layers within distributed environments. As a consequence, the software layer can be seen as integrating entities (filters, traces and agents) transparently operating over and communicating with any local or distant agent. Traces are processed and enriched under two simultaneous threads: by agents (computation of application or visualization properties), and by norms (evaluation of consistency and privacy). The whole process may be seen as 
the exploration of traces as long as it is fruitful to do so.

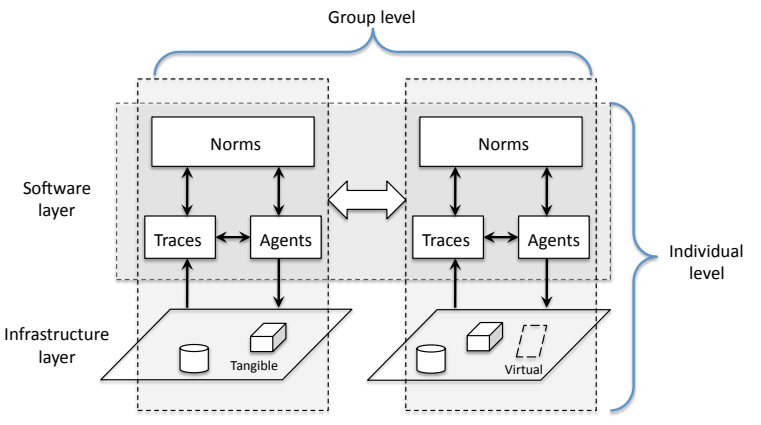

Figure 2: Collaboration as an exploratory process driven by norms.

This architecture model (Figure 2) allows the development of situated, spontaneous activities, mediated by tangible tools and norms.

\section{Conclusion}

To cope with the potential complexity of tangible collaboration through distant surfaces, we have proposed a modeling based on normative multi-agent approach and defined collaboration as a trace-based process regulated by norms operating at various levels. The potential of our approach with respect to activity theory lies in the possibility of explicitly formulating and exploiting sets of norms operating at several levels, from physical to social levels. These norms do not act as a prerequisite, or as a way to apply a priori constraints on action. Rather, they result in a set of signs enriching the trace and therefore situating the activity. Such design offers novel ways for embedding activity theory in the current trend of physico-social computing.
Work supported by ANR under grant IMAGIT - ANR 2010 CORD 01701.

\section{References}

[1] O. Boissier, F. Balbo, and F. Badeig. Controlling multiparty interaction within normative multi-agent organisations. In Coordination, Organization, Institutions and Norms in Agent Systems VI, volume LNAI 6541, pages 259-294, 2011.

[2] G. Bourguin, A. Derycke, and J. C. Tarby. Beyond the interface: co-evolution inside interactive systems a proposal founded on activity theory. In $\mathrm{IHM}-\mathrm{HCl}$ conference, People and computer XV - Interactions without Frontiers, pages 297-310, 2001.

[3] H. H. Clark and E. F. Schaefer. Contributing to discourse. In Cognitive Science, pages 259-294, 1989.

[4] C. Dumazeau and L. Karsenty. Communications distantes en situation de travail. In "Le travail humain", PUF, pages 225-252, 2008.

[5] Y. Engestrm. Learning by Expanding: an activity-theoretical approach to developmental research. Orienta-Konsultit Oy, 1987.

[6] R. E. Kraut, R. Fussell, and J. Siegel. Visual information as a conversational resource in collaborative physical tasks. In $\mathrm{HCl}$, pages 13-49, 2003.

[7] S. Lepreux, S. Kubicki, C. Kolski, and J. Caelen. Distributed interactive surfaces using tangible and virtual objects. In Workshop DUI'2011 "Distributed User Interfaces", at CHI'2011, pages 65-68, 2011.

[8] J. A. Pape and T. C. N. Graham. Coordination policies for tabletop gaming. In Graphics Interface Poster, pages 24-25, 2010.

[9] O. Shaer and E. Hornecker. Tangible user interfaces: Past, present and future directions. In $\mathrm{HCl}$, pages 1 138,2010 